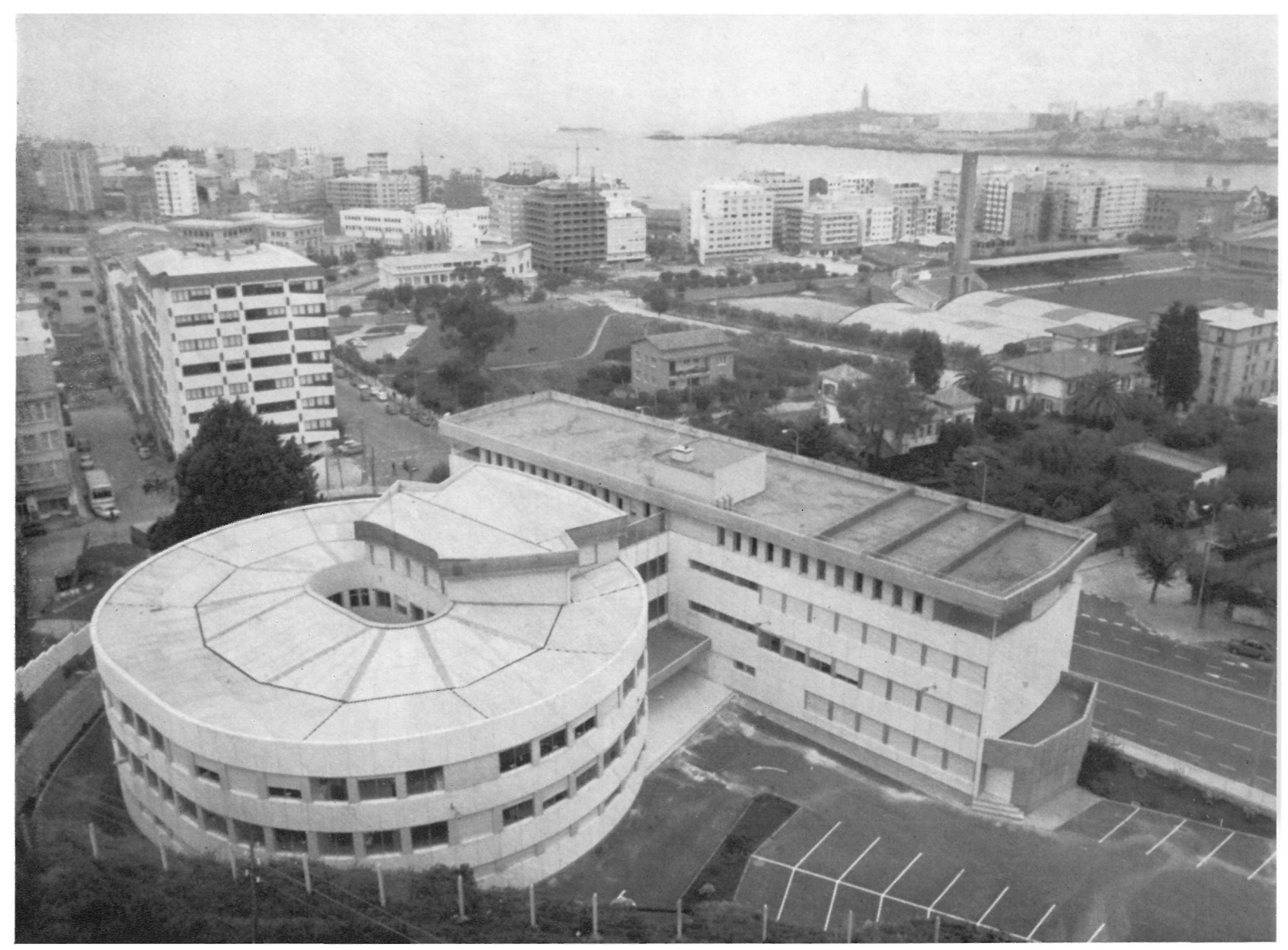

\title{
jefatura Provincial de Sanidad La Coruña • España
}

A. BOTELLA, Dr. arquitecto

$131-114$

\section{sinopsis}

Este complejo edificado, que alberga oficinas, dispensarios y viviencios, se ha resuelto acertadamente conjugando los diversos locales y sus usos respectivos, con las circulaciones diferenciadas $e$ independientes que requieren.

En el artículo se describen esquemáticamente la distribución, funcionamiento, materiales y construcción del edi-
Los edificios destinados a Jefaturas Provinciales de Sanidad suelen tener cierta complejidad, dado que deben reunir locales para tres usos distintos con circulaciones diferenciadas e independientes entre sí, como son:

- Oficinas administrativas generales, despachos y dirección.

- Dispensarios, consultas externas y laboratorios.

— Viviendas de jefes y empleados.

Esta Jefatura para La Coruña, de reciente terminación, se ha adaptado al máximo, en planta, a la forma irregular del solar, 


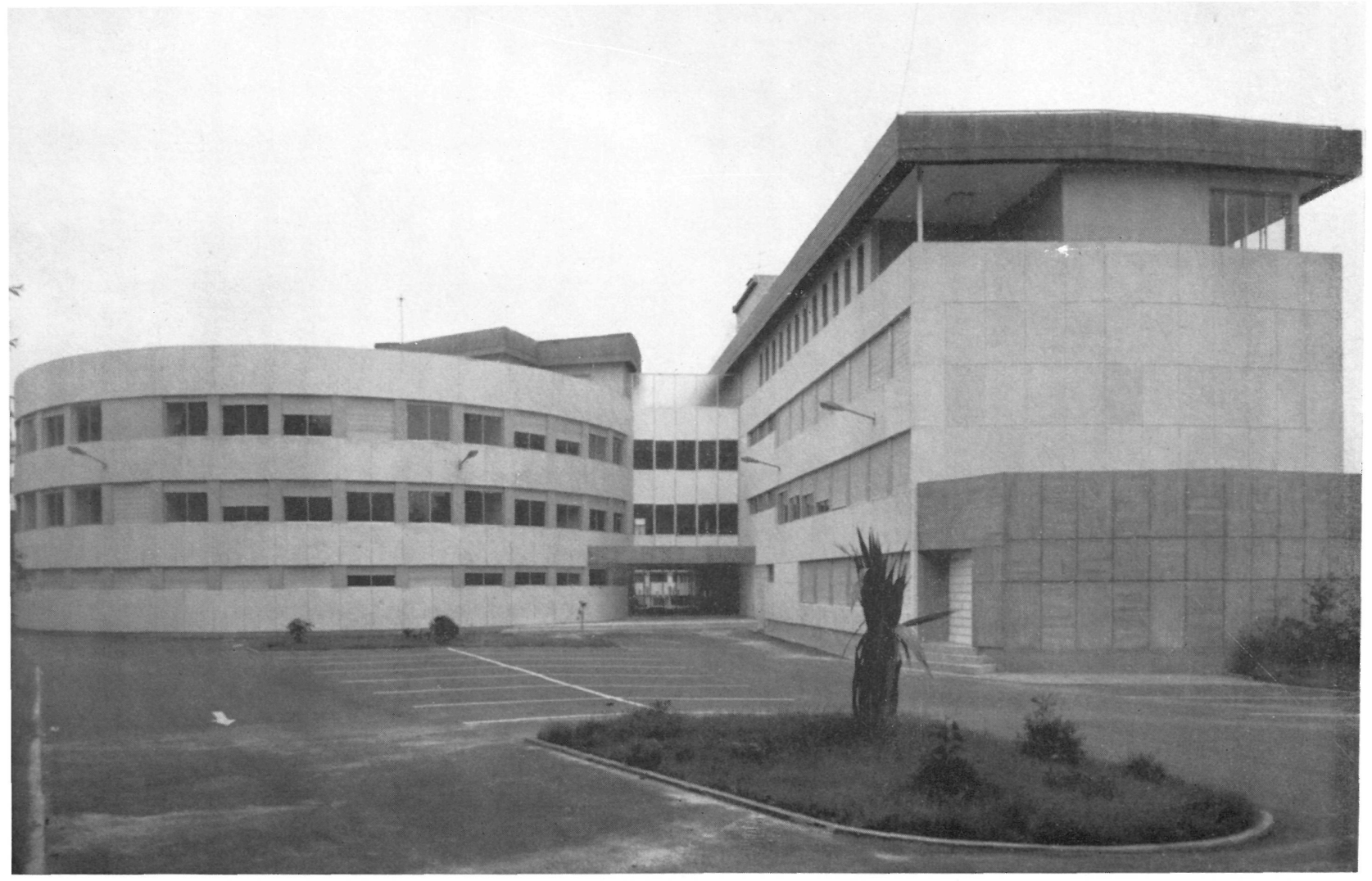

disponiendo los accesos por el Paseo de Ronda y Avda. de la Habana, resultando un edificio que consta principalmente de dos cuerpos totalmente diferenciados:

- Un cuerpo lineal de doble crujía y cuatro plantas, situado en fachada al Paseo de Ronda y destinado a las oficinas de la Jefatura Provincial. En planta cuarta están las viviendas de jefe y subjefe de Sanidad.

- Otro cuerpo posterior de forma circular y tres plantas, situado en el interior del solar, donde se ubican todas las consultas internas y los laboratorios.

Estos dos cuerpos quedan conectados entre sí por un elemento de unión, situado junto a los enlaces verticales de ascensores, escaleras y entradas de planta baja y que permite el enlace con todas las plantas.

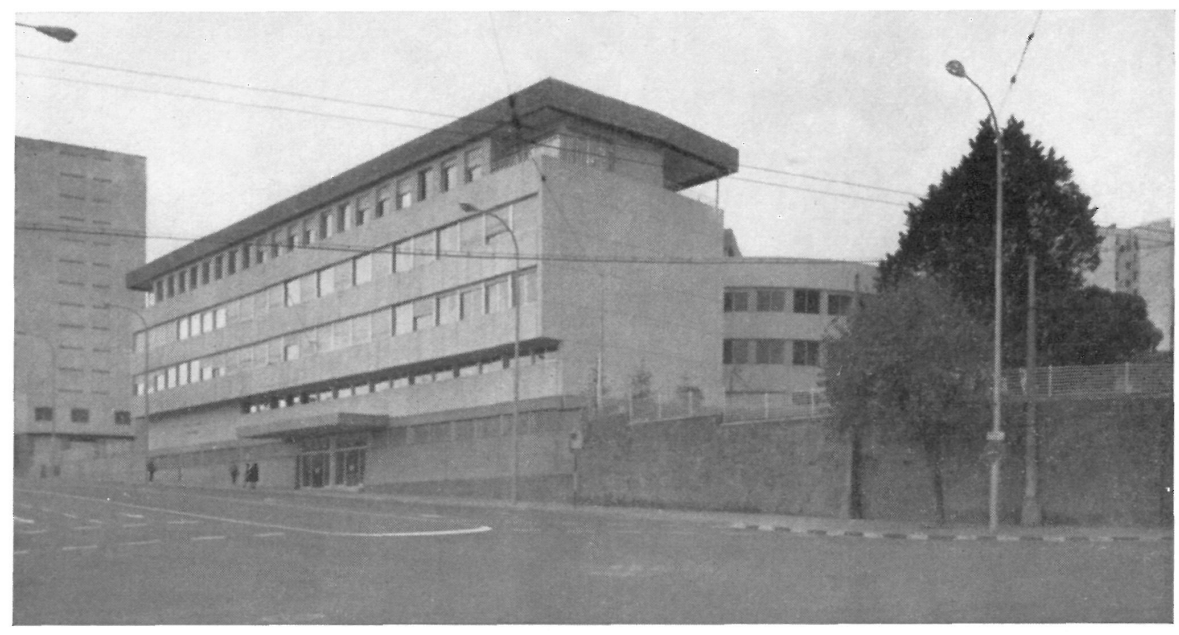




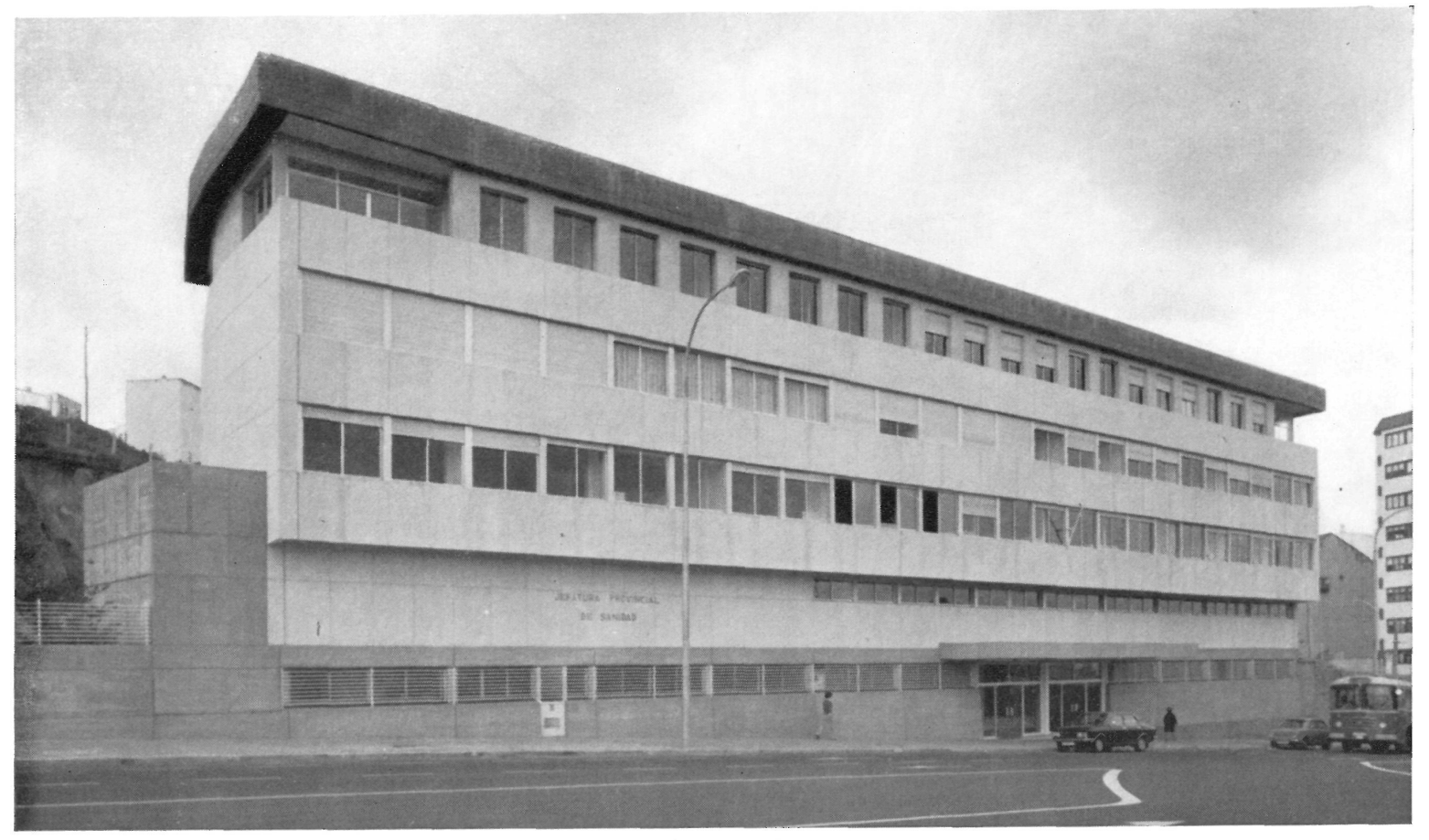

El complejo edificado ha sido realizado a base de estructura metálica resistente y cerramientos de fachada con piezas prefabricadas de piedra artificial.

El resto de los materiales y acabados son normales, con carpintería de aluminio, terrazo en solados y alicatados de color, resultando a unos precios razonables de menos de 10.000 pesetas el $\mathrm{m}^{2}$.

La utilización del edificio y su funcionalismo se patentiza al exterior, y tanto su distribución como su fisonomía son lógica consecuencia del correcto desarrollo del organigrama propuesto.

FOTOS: BLANCO
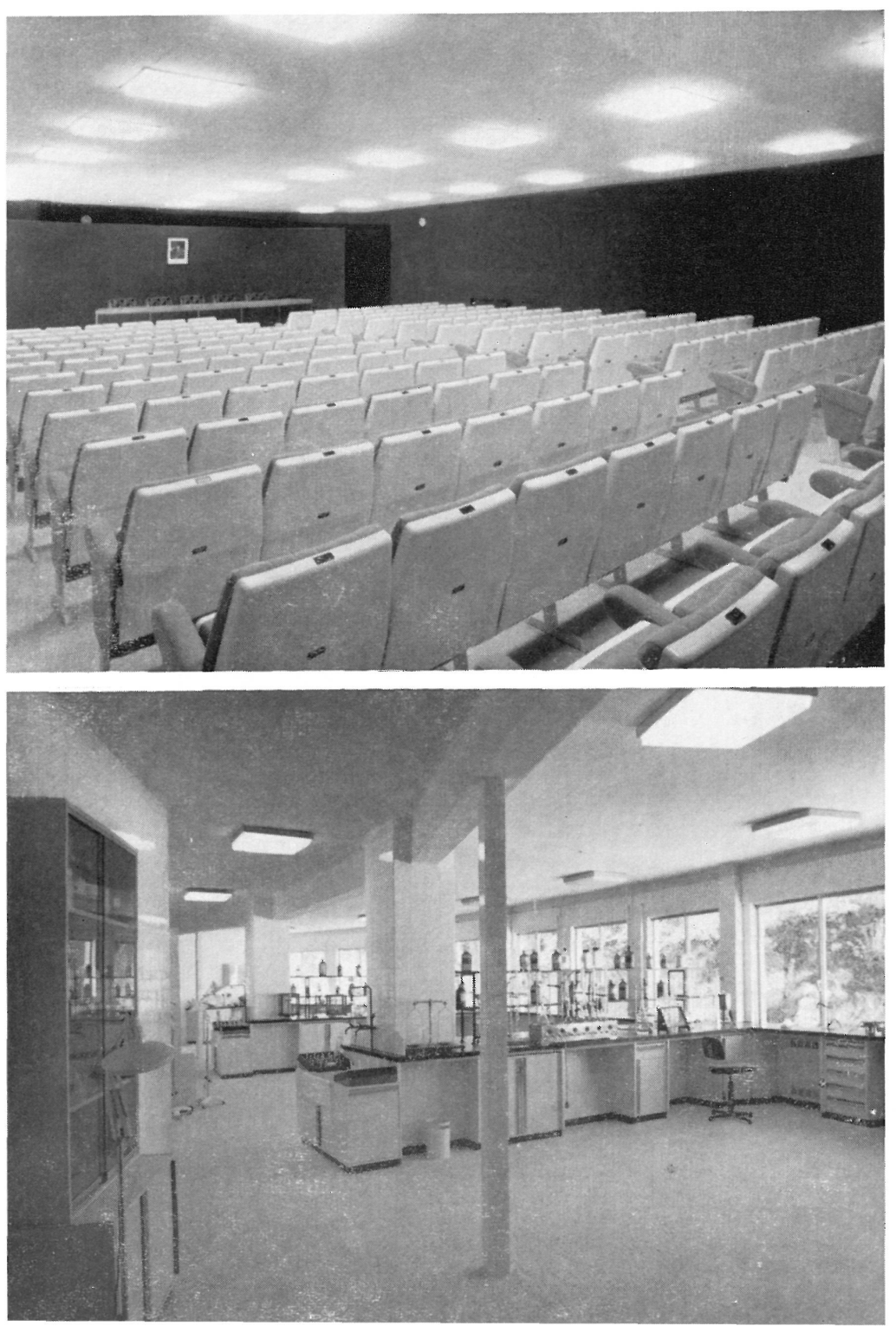


\section{situación}
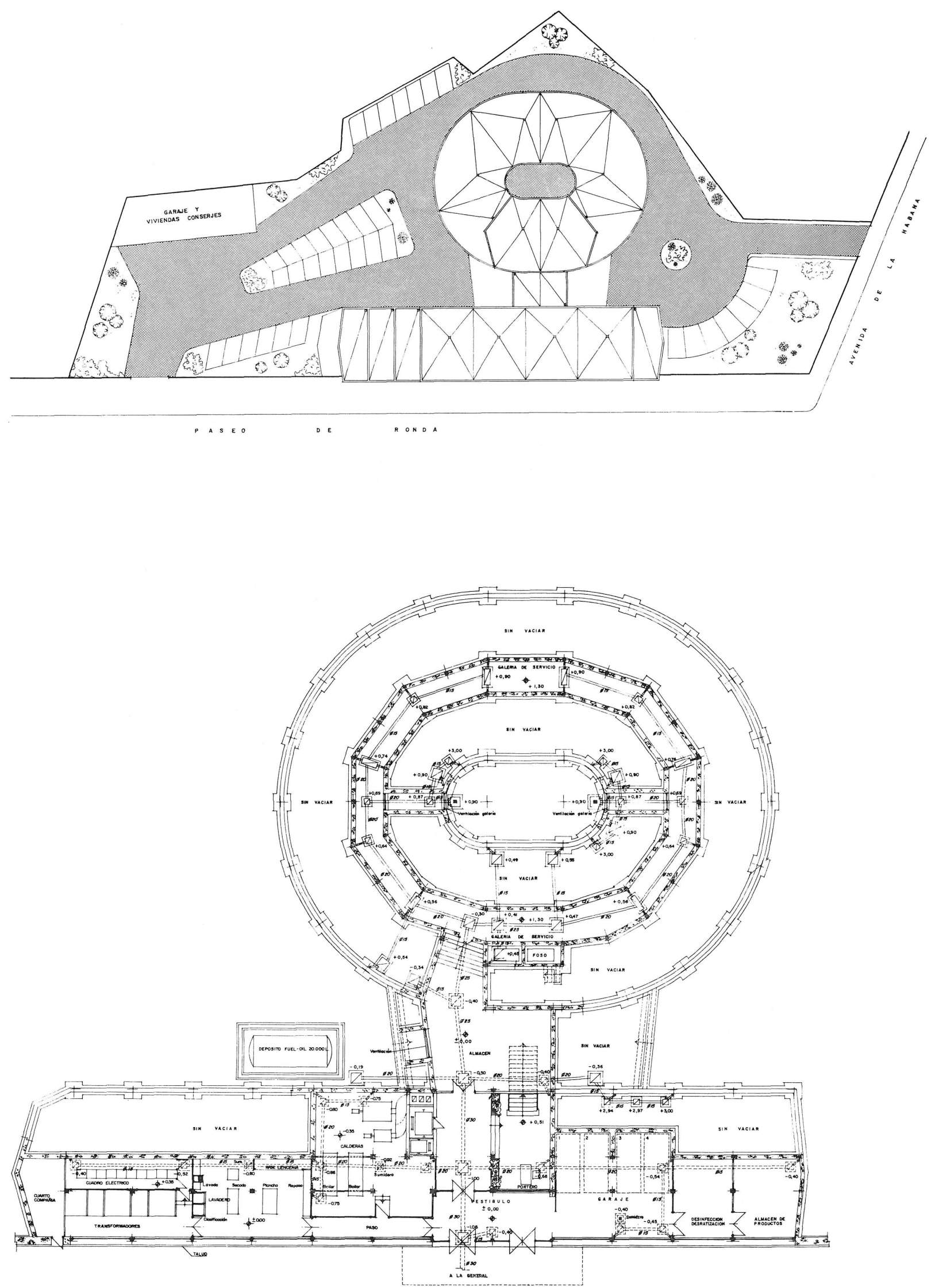

\section{planta de semi-sótano}



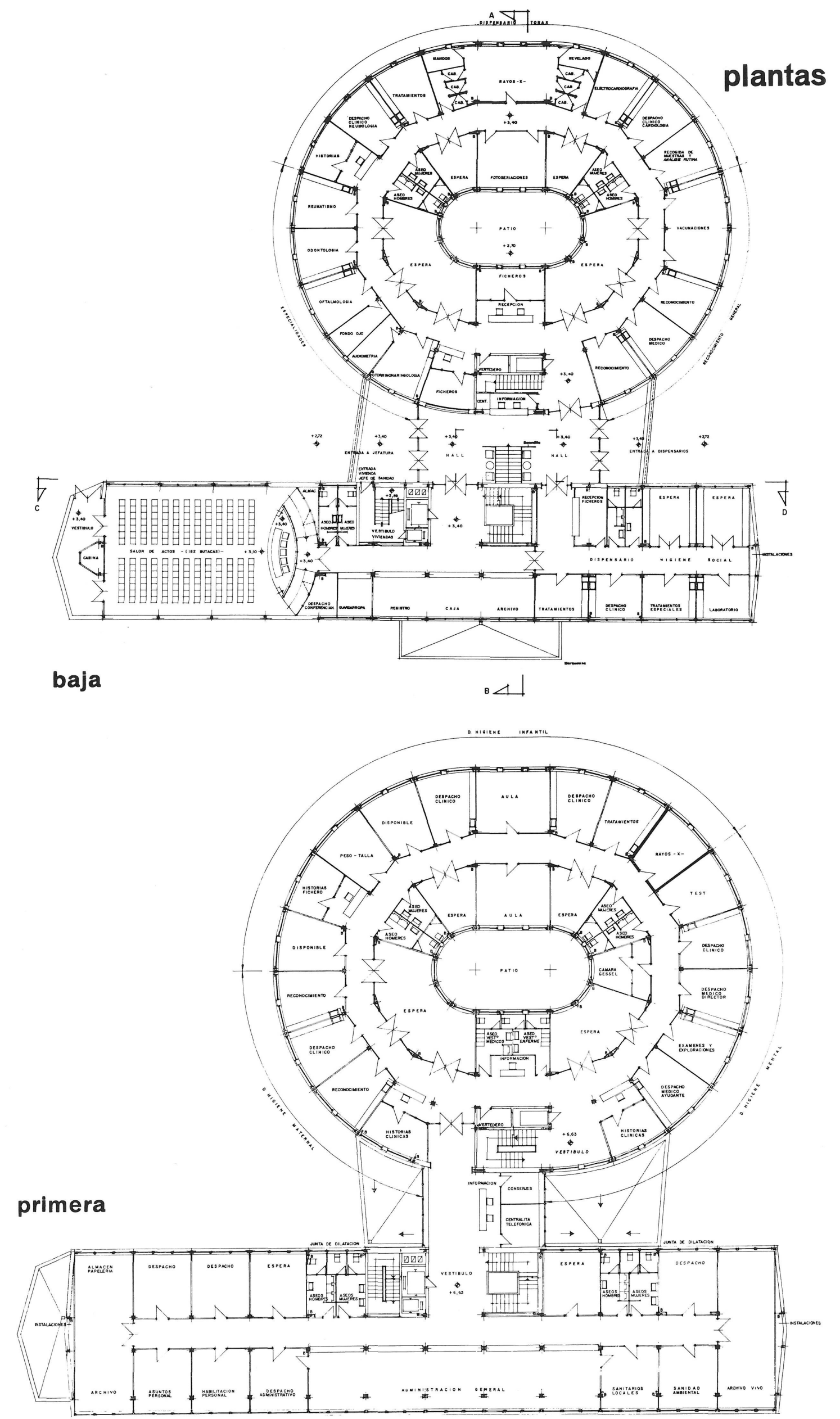


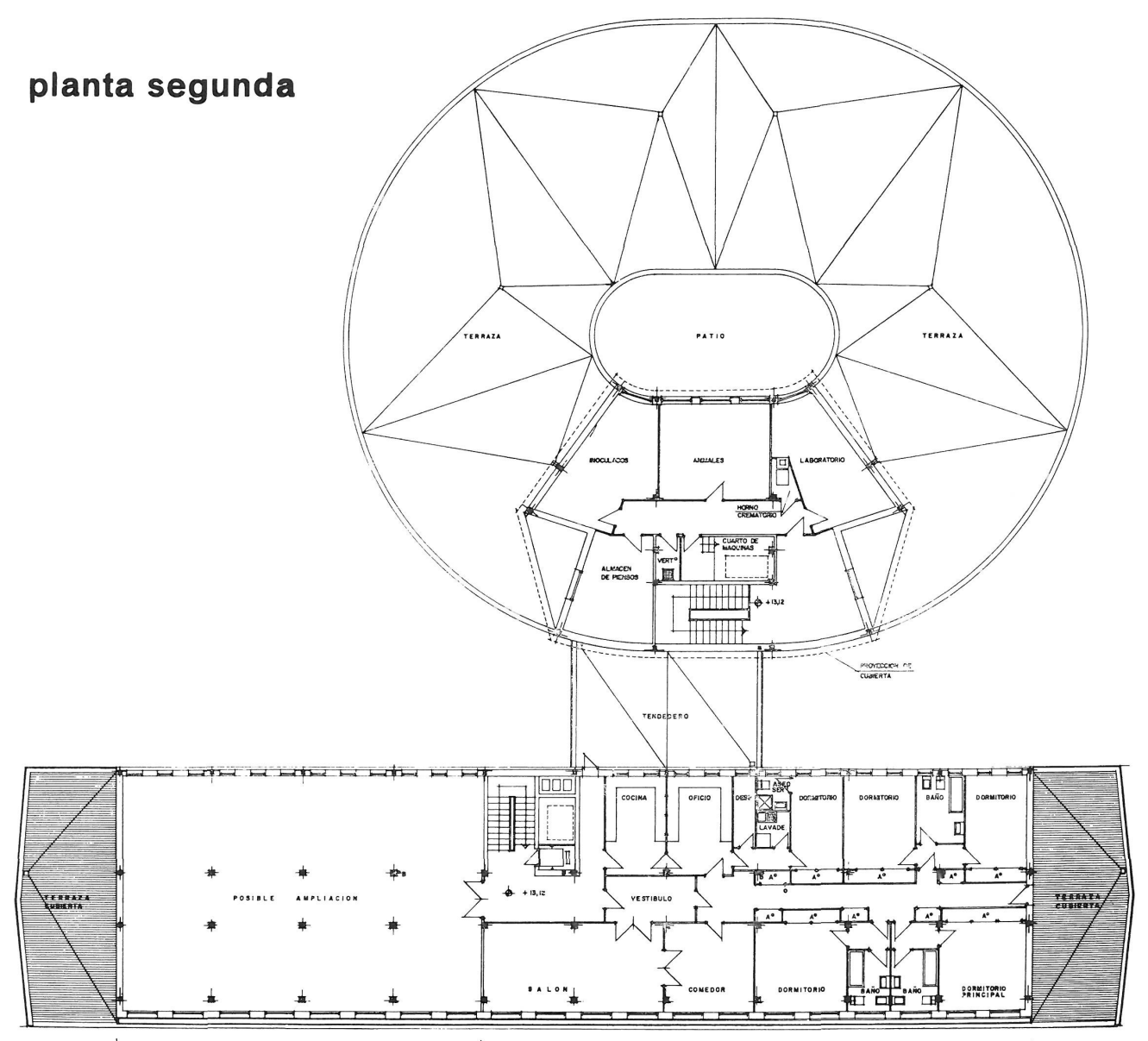

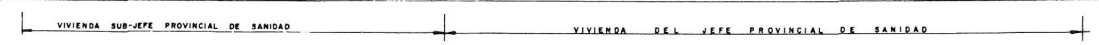

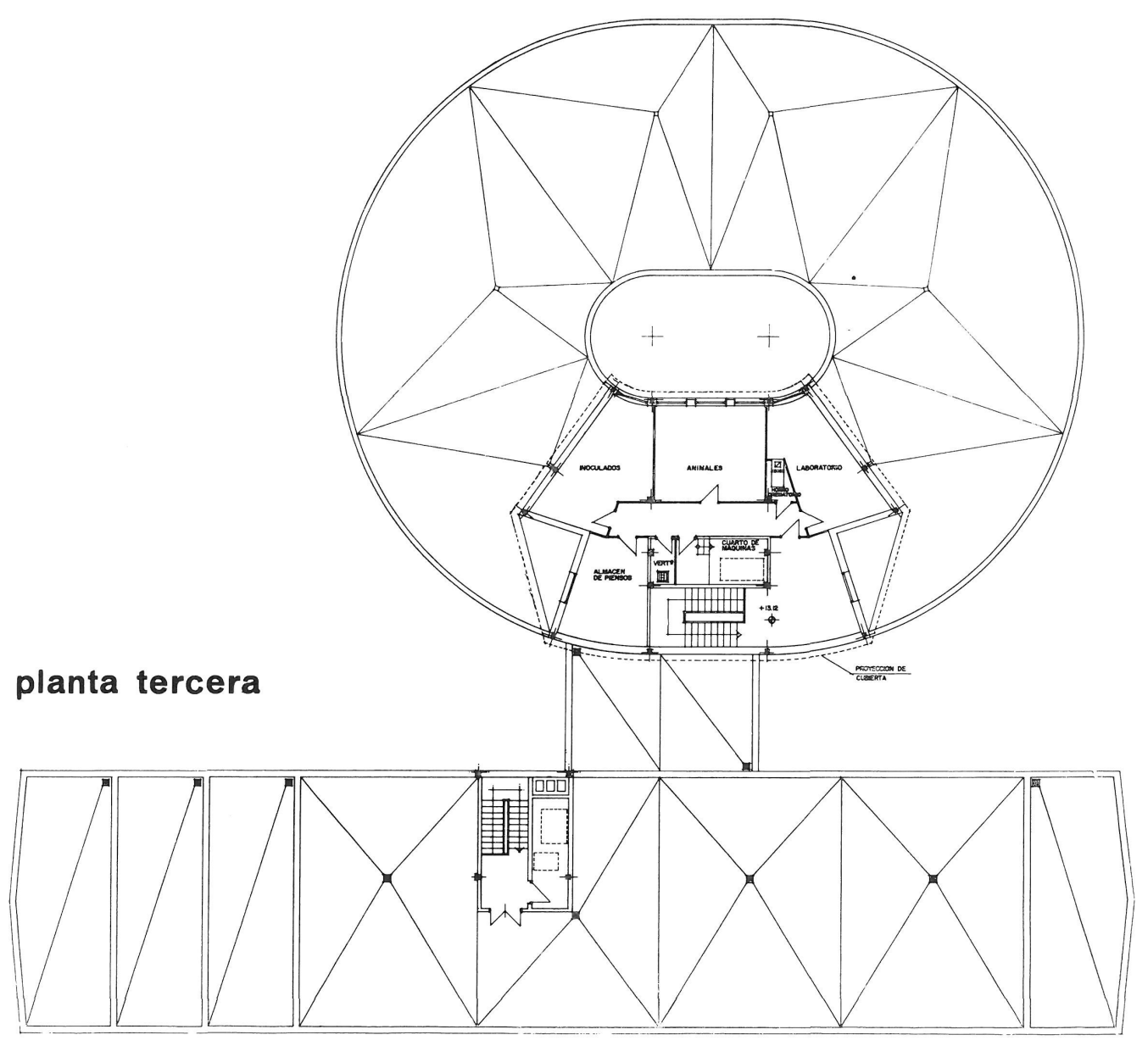



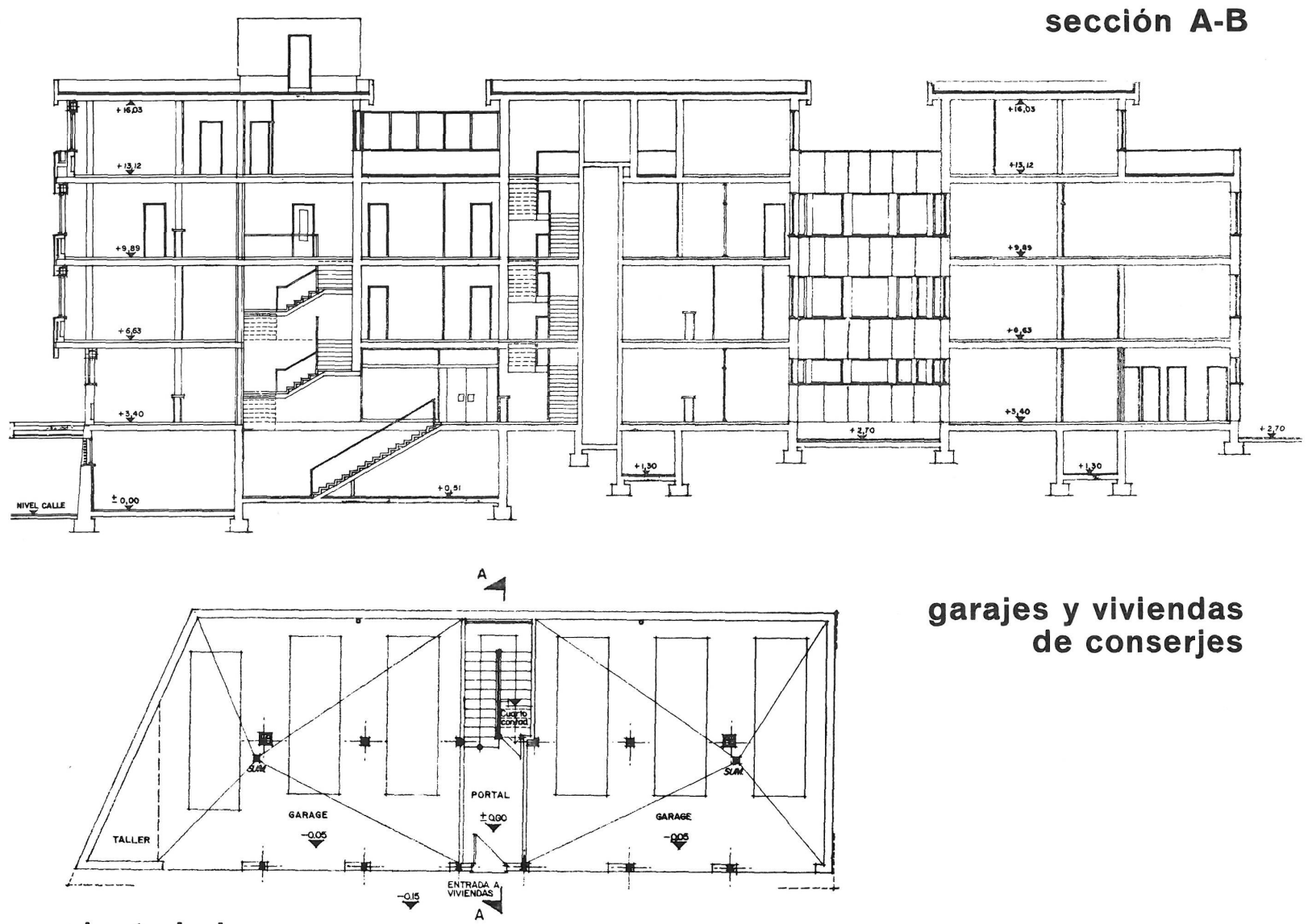

garajes y viviendas de conserjes

planta baja

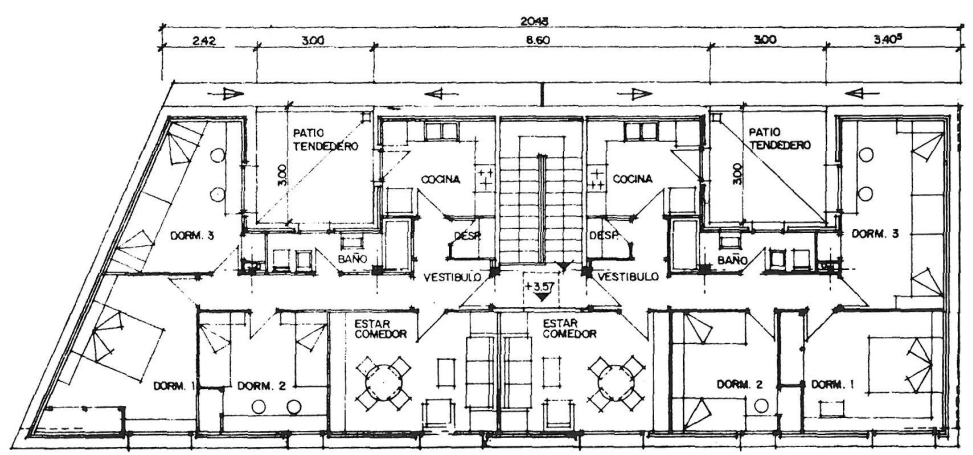

planta alta

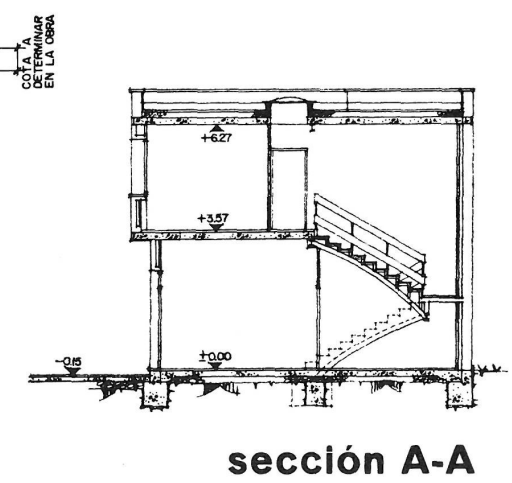

\section{résumé}

Direction Provinciale de Santé. La Corogne - Espagne

A. Botella, Dr. architecte

Cet ensemble bâti, qui abrite des bureaux, dispensaires et logements, entre autre conjuguant les divers locaux et leurs usa ges respectifs, avec les circulations différenciées et indépendantes qu'ils requièrent.

Dans cet article, l'auteur décrit schémati quement la distribution, le fonctionnement les matériaux et la construction du ba-

\section{summary}

Provincial Health head office. La Coruña - Spain

A. Botella, Dr. arch.

This complex with offices, dispensaries and housings, among other services, is in that it links the various premises project ing to their respective use by means of the differentiated and independent connect ing corridors they require.

The articde gives a schematic description of the function, distribution, materials and

\section{zusammenfassung \\ Landesgesundheitsbehörde. La Coruña - Spanien}

A. Botella, Dr. Arch.

Dieses Komplex mit Büros, Polikliniken und Wohnungen ist ein gut geplantes und ausgefürtes Projekt, da es die verschiedenen Lokale gemäss ihrem Gebrauch durch getrennt und unabhängige Korridors mitteinander verbinden.

Der Artikel beschreibt schematisch die Funktion, Verteilung, Materialien und die 